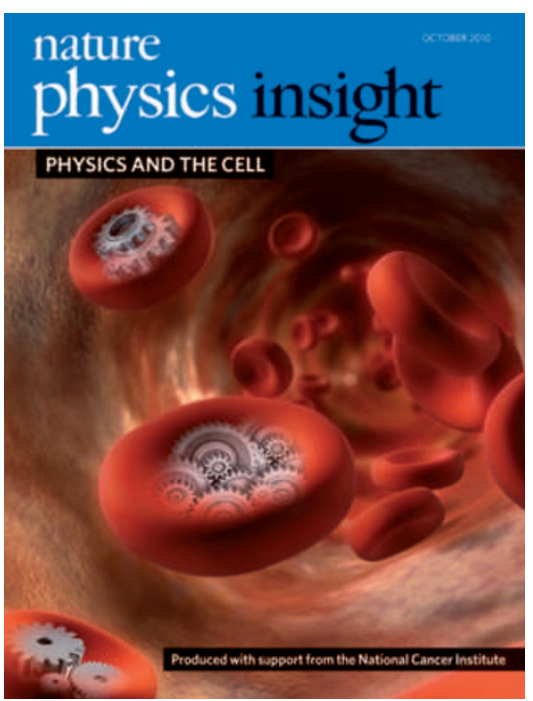

\section{COVER IMAGE}

Looking at cells from a mechanical viewpoint can provide insight into their behaviour and function that is not available through more empirical approaches. Numerical techniques and material-characterization experiments common in many physics laboratories are now proving to be useful tools in biology too. All images iStockphoto: main,

Henrik Jonsson; cogs L-R: Mark Stay, Christian Lagereek, Pagadesign.

\section{NPG LONDON}

The Macmillan Building,

4 Crinan Street, London N1 9XW

$\mathrm{T}:+442078334000$

F: +442078434563

naturephysics@nature.com

EDITOR

ALISON WRIGHT

INSIGHT EDITOR

DAVID GEVAUX

SENIOR COPY EDITOR

JANE MORRIS

PRODUCTION EDITOR

JENNY MARSDEN

ART EDITOR

DAVID SHAND

EDITORIAL ADMIN. SUPERVISOR CECILIA VAKALOUDI

MARKETING MANAGER

BHAVNA TAILOR

PUBLISHING DIRECTOR

JASON WILDE

EDITOR-IN-CHIEF,

NATURE PUBLICATIONS

PHILIP CAMPBELL

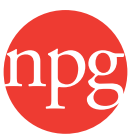

nature publishing group

\title{
Physics and the cell
}

A quick glance at the titles of the research papers in an interdisciplinary journal such as Nature or Science will probably tell you that the languages of biologists and physicists can be far removed. From a physical-sciences perspective, the abstract of a biology paper can sound like a recipe for some truly unpleasant dish. This hardly encourages a physicist to read any further. Yet physicists have historically played an important role in developing many of the cornerstone theories of modern biology and, although the dichotomic view of the quantitative physicist and the descriptive biologist is not as true as it once was, it is certain that some of the approaches common in physics could provide further insight and understanding in the future when applied to biological systems.

Biophysics is far from a new concept, but where does physics end and biology begin? For a manuscript editor of a research journal at least, this is more than merely a philosophical question: does a particular study belong in a physics or a biology journal? There is no doubt that, if there is a boundary at all, it is constantly shifting and depends very much on your individual perspective. We would certainly welcome your thoughts.
But the question for now is: how do we make problems in biology more accessible to a modern physicist? The aim of this Nature Physics Insight is to do just this with a few areas of research from contemporary biophysics. It is customary to say in the introduction to such a collection that the topics covered are not exhaustive. This is, of course, particularly true in this case where the subjects could come from anywhere within the massive scope of the biological sciences. One criterion was a focus on ways physics can be used to understand the natural process of the cell, rather than on the many emerging techniques for probing cells - optical tweezers, imaging and microscopy or medical nanotechnologies or, to look at it in the other direction, technologies inspired by nature, for example, DNA electronics. But even excluding all these exciting areas of research there are still so many possibilities. We can only provide a small cross-section, but we hope this taster will inspire you to read more: you might even be able to contribute to the field, and perhaps more than you first think.

Finally, we would like to extend our sincere thanks to our sponsor, the National Cancer Institute, for their support. Of course, Nature Publishing Group takes complete responsibility for the editorial content.

David Gevaux, Senior Editor

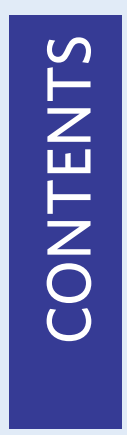

\section{PERSPECTIVE}

Physics challenged by cells

Ana-Sunčana Smith

\section{COMMENTARY}

\section{Are biomechanical changes necessary for} tumour progression?

Anatol Fritsch, Michael Höckel, Tobias Kiessling,

Kenechukwu David Nnetu, Franziska Wetzel, Mareike Zink and Josef A. Käs

\section{REVIEW ARTICLES}

\section{Physical virology}

W. H. Roos, R. Bruinsma and G. J. L.Wuite

Emergent complex neural dynamics

Dante R. Chialvo

Challenges in protein-folding simulations

Peter L. Freddolino, Christopher B. Harrison, Yanxin Liu and Klaus Schulten 